\title{
REESTRUTURAÇÃO PRODUTIVA E DO ESPAÇO NO RIO DE JANEIRO: UMA ANÁLISE REGIONAL A PARTIR DO VALE DO PARAÍBA FLUMINENSE
}

\section{Productive and space restructuring in Rio de Janeiro: a regional analysis of the Paraíba Fluminense Valley}

\author{
Regina Helena Tunes \\ Professora Adjunta do Departamento de Geografia Humana do IGEOG e Docente \\ do PPGEO da UERJ \\ tunesregina@gmail.com
}

Artigo enviado para publicação em 07/11/2019 e aceito em 11/11/2019

DOI: $10.12957 /$ tamoios.2019.46147

\begin{abstract}
Resumo
A análise da relação entre a dinâmica produtiva e a dinâmica do espaço é a questão central desse texto a partir da análise da região do Vale do Paraíba fluminense. Essa região tem apresentando um dinamismo econômico, com destaque para a atividade industrial, que se constitui hoje em um contraponto ao movimento geral do estado do Rio de Janeiro. Isso significa dizer que enquanto o território fluminense vem apresentando decréscimos da indústria e de outros setores econômicos, a região, desde fins do século passado, apresenta vertiginoso crescimento industrial e econômico centrado no setor metal-mecânico. Para isso o texto foi construído a partir de amplo levantamento bibliográfico, análise e sistematização de dados estatísticos sobre a dinâmica econômica e trabalho de campo realizado nos municípios da região. Diferentemente das interpretações que apontam uma reindustrialização regional, discutimos no texto o entendimento de uma profunda reestruturação regional que abarca a produção e a dinâmica espacial de forma imbricada. Entendese, por fim, que as atuais transformações produtivas e espaciais guardam estreita relação com o processo de metropolização do espaço.
\end{abstract}

Palavras-Chave: Reestruturação; Indústria; Inovação; Metropolização.

\begin{abstract}
The analysis of the relationship between the productive dynamics and the space dynamics is the central issue of this text from the analysis of the Paraiba Fluminense Valley region. This region has shown an economic dynamism, with emphasis on industrial activity, which is today a counterpoint to the general movement of the state of Rio de Janeiro. This means that while the state of Rio de Janeiro has been showing decreases in industry and other economic sectors, the region, since the end of the last century, has been experiencing dizzying industrial and economic growth centered on the metal-mechanical sector. For this, the text was built from a broad bibliographic survey, analysis and systematization of statistical data on the economic dynamics and fieldwork carried out in the municipalities of the region. Unlike the interpretations that point to a regional reindustrialization, we discuss in the text the understanding of a deep regional restructuring that encompasses production and spatial dynamics in an imbricated way. Finally, it is understood that the current productive and spatial transformations are closely related to the process of space metropolization.
\end{abstract}

Keyword: Reestruturation; Industry; Inovation; Metropolization. 


\section{Introdução}

Refletir sobre a Geografia Econômica fluminense contemporânea é o desafio maior desse texto e preocupação fundamental que estamos trilhando a partir do projeto de pesquisa em andamento intitulado "Geografia Econômica contemporânea no Rio de Janeiro: novos desafios, antigos dilemas" 1 .

Esse projeto de pesquisa se insere na análise das relações entre espaço e economia a partir do pressuposto apontado por Claval (2005, p.23) de que "decisões dos agentes econômicos sempre tem dimensões espaciais", o que significa dizer, em outras palavras e tomando agora as de Santos $(2003$, p.20) que "(...) a economia se realiza no espaço e não pode ser entendida fora desse quadro de referência".

Partindo assim de uma leitura teórica-conceitual fundada no campo da Geografia Econômica, que tem um aspecto interdisciplinar que lhe é inerente (SPOSITO, 2019), esse texto tem o objetivo geral de compreender a relação entre a produção do espaço e os agentes econômicos que atuam sobre esse espaço a partir de uma perspectiva multiescalar.

Especificamente, temos como objetivo nesse texto analisar as transformações produtivas e espaciais, entendendo-as de forma imbricada, na região do Vale do Paraíba fluminense a partir da última década do século passado, período a partir do qual a região passa por uma profunda transformação produtiva inaugurando um novo ciclo de acumulação regional.

A hipótese que colocamos para debate é de que há uma relação entre as transformações produtivas e as espaciais da região que além de evidenciar elementos marcantes do processo de reestruturação produtiva, se liga também, em termos de dinâmica espacial, à integração ao processo de metropolização do espaço.

Nesse sentido que consideramos a análise multiescalar, pois se parte da análise regional buscando estabelecer relações com processos que são homogeneizantes por um lado, mas que na verdade contribuem para o aprofundamento da diferenciação e hierarquização dos lugares.

Admite-se, de antemão, que a análise dos agentes econômicos privilegia o movimento do capital industrial e das atividades de serviços diretamente associadas a ele chamados a partir de agora simplesmente de capital produtivo ${ }^{2}$.

Claval (2005) aponta que os estudos de Geografia Econômica, após um período de ostracismo na Geografia, vêm crescendo na ciência geográfica e isso é justificado pelo autor pelas recentes transformações associadas ao mundo do trabalho, a intensificação dos fluxos mundiais e, em termos de dinâmica espacial, ao processo de metropolização do espaço.

Esse texto se insere justamente dentro desse debate apontado por Claval (2005) ao analisar, na questão do mundo do trabalho e a partir do processo de reestruturação produtiva, a relação entre a produção do espaço e o capital produtivo no estado do Rio de Janeiro.

Optou-se, nesse texto, pela análise regional a partir do Vale do Paraíba fluminense por essa região apresentar hoje um dinamismo econômico e produtivo singular, na contramão da crise da indústria e decréscimo econômico do estado do Rio de Janeiro, ao mesmo tempo em que dada a sua localização estratégica entre as duas maiores metrópoles brasileiras (Rio de Janeiro e São Paulo), e acredita-se que esse é um dado importante na compreensão do dinamismo econômico diferenciado da região, permite uma relação com o processo de metropolização do espaço.

Para essa discussão o texto estrutura-se em três partes. O ponto de partida é a análise do dinamismo econômico e industrial recente do Vale do Paraíba fluminense que apresenta uma peculiaridade no contexto fluminense, o que inclusive justifica a análise 
dessa região. Essa região apresenta hoje um contraponto ao cenário de crise conjuntural da indústria e de outras atividades econômicas em relação ao estado do Rio de Janeiro. Enquanto o estado do Rio de Janeiro vê diminuir cada vez mais a participação da indústria no PIB estadual, essa região, ao contrário disso, apresenta indícios do fortalecimento da indústria.

Na segunda parte do texto enfocamos especialmente a dinâmica industrial regional a partir de uma perspectiva histórica que procura desvendar a relação espaço e economia industrial na região. O foco dessa parte do texto é tensionar o debate do contraponto industrial como um elemento que evidencia um forte processo de reestruturação produtiva regional. Porém, ainda que regional, é revelador, a nosso ver, de uma dinâmica do espaço e do capital que transcende os limites regionais e estaduais.

Na terceira e última parte do texto e, a partir da evidência das transformações no espaço e no capital no âmbito regional ligado diretamente à dinâmica espacial em escala maior, buscamos evidenciar a relação entre as transformações urbanas regionais ao processo de metropolização do espaço.

\section{O ponto de partida: o dinamismo econômico-industrial contemporâneo da região do Vale do Paraíba Fluminense.}

Nessa primeira parte do texto nosso objetivo é apresentar e discutir os argumentos que justificam a escolha da região do Vale do Paraíba fluminense como foco central nesse artigo. Considera-se fundamental essa justificativa por não se tratar de uma escolha aleatória ou mesmo um estudo de caso ${ }^{3}$.

Ao contrário disso, a dinâmica econômica diferenciada da região em relação ao estado do Rio de Janeiro, tanto do ponto de vista quantitativo como qualitativo, justifica o recorte regional. E é essa análise o norte dessa primeira parte do texto.

A região se destaca por representar hoje um contraponto em relação ao decréscimo produtivo do estado do Rio de Janeiro que os dados da indústria de transformação comprovam. Mas também, para além de uma questão apenas estatística, podemos afirmar que a região tem apresentando recentemente uma dinâmica econômica de natureza diferenciada a partir do desenvolvimento de atividades inovadoras no processo produtivo e relacionadas à indústria de transformação ${ }^{4}$.

Assim, trata-se de uma região de especial interesse para compreender a relação entre o capital produtivo e a produção do espaço. Ainda que o recorte regional seja o privilegiado no texto é importante esclarecer que a análise parte da escala regional buscando as conexões com as redes nacionais e globais de produção.

A região do Vale do Paraíba fluminense é composta por 9 municípios (Barra Mansa, Itatiaia, Pinheiral, Piraí, Porto Real, Quatis, Resende, Rio Claro e Volta Redonda) e está localizada na porção mais ao sul do estado do Rio de Janeiro como mostra o mapa a seguir. Reúne uma população, segundo dados do IBGE $^{5}$ para o ano de 2016 , de pouco mais de 1 milhão de habitantes, PIB per capita maior do que a média do estado do Rio de Janeiro, ainda que menor do que do Noroeste Fluminense, e de forte especialização produtiva hoje no ramo automobilístico e metal-mecânico. 


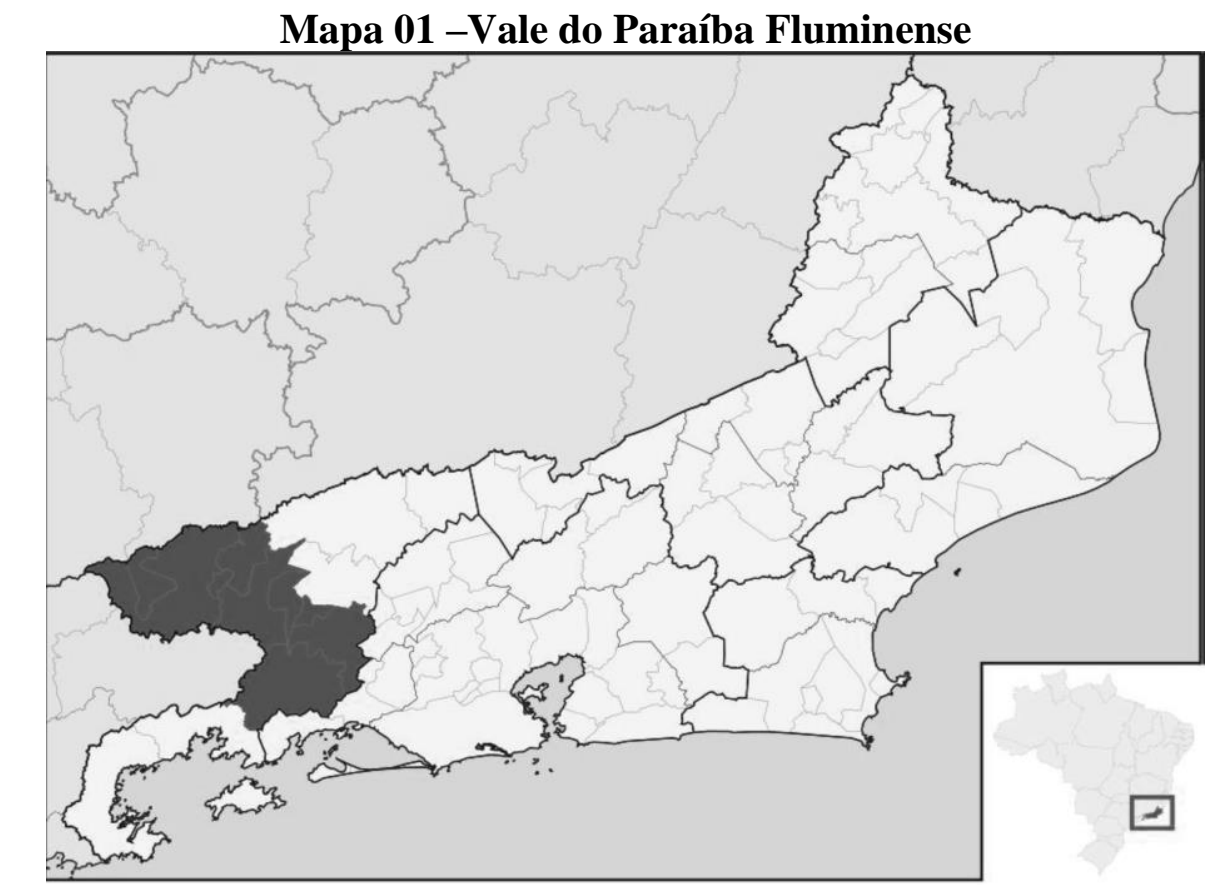

Fonte: https://pt.map-of-rio-de-janeiro.com/pdf/vale-do-para\%C3\%ADbafluminense-mapa-em-pdf.pdf. Acesso em 01/05/19.

O estado do Rio de Janeiro vem perdendo importância relativa na atividade industrial de transformação desde 1970. Segundo dados do Censo Industrial do IBGE em 1970 a indústria fluminense respondia por $15,7 \%$ da indústria brasileira, ficando atrás apenas do estado de São Paulo. Já na primeira década do novo século, o Rio de Janeiro é ultrapassado por Minas Gerais, configurando como o terceiro estado industrial. Em 2016 o Rio passa a ser apenas o $6^{\circ}$ maior estado industrial, com uma participação relativa de $5,17 \%$, o menor valor historicamente do estado, sendo passado também pelo Rio Grande do Sul, Santa Catarina e Paraná.

Em termos de estabelecimentos da indústria de transformação, o período de 2002 a 2017 registra dois movimentos distintos. De 2002 a 2015, segundo dados da RAIS ${ }^{6}$, o número de estabelecimentos industriais cresceu no estado, já a partir de 2015 registra-se uma perda absoluta de estabelecimentos industriais. Entre 2015 e 2017 são encerradas, segundo a mesma fonte, mais de 10 mil estabelecimentos industriais. Ainda que em números absolutos o primeiro período registre crescimento é importante enfatizar que a indústria fluminense perdeu espaço do ponto de vista relativo para outros estados brasileiros nesse período.

Foram os anos de 2015 a 2017 o período de menor crescimento econômico do estado o que pode ser explicado pela análise conjunta de dois dados: pela redução do preço do petróleo bruto internacional ${ }^{7}$ e pela excessiva especialização produtiva do estado na extração e processamento do petróleo ${ }^{8}$. Segundo dados da Fundação Centro Estadual de Estatísticas, Pesquisas e Formação de Servidores Públicos do Rio de Janeiro (CEPERJ), o PIB industrial fluminense retraiu na comparação do período 4,3\%. Se olharmos apenas a indústria de transformação chegamos a-9,4\% do PIB.

O Valor de Transformação Industrial (VTI) do período entre 2014 a 2016 também comprovam o decréscimo industrial do estado. Segundo dados do $\mathrm{IBGE}^{9}$, a partir de 2015 o VTI industrial registra um dinamismo negativo da ordem de $5 \%$ ao ano.

Esse desempenho negativo da indústria de transformação fluminense repercute também na diminuição da força de trabalho industrial. Segundo dados do IBGE, a partir 
de 2014 o número de pessoas ocupadas na atividade industrial começa a decair, sendo maior o decréscimo nos anos de 2015 e 2016 . Ao total, entre 2013 e 2016, foram perdidos mais de 100 mil postos de trabalho na atividade industrial.

Concluímos assim que a dinâmica industrial do estado do Rio de Janeiro nos últimos anos, especialmente entre 2014 a 2016, registra forte queda no número de estabelecimentos industriais, no pessoal ocupado e no VTI. Queda esta que se apresenta não apenas de forma relativa, mas, como vimos, absoluta também, o que nos leva a considerar o debate sobre a desindustrialização do estado do Rio de Janeiro.

Entende-se por desindustrialização o processo de diminuição relativa e absoluta da participação da indústria na estrutura produtiva de uma área. Isso significa que além do crescimento mais significativo de outros setores econômicos em relação ao industrial, há também um decréscimo quantitativo bruto da produção industrial que pode ser medida através da análise dos dados de estabelecimentos e produção industrial.

Nassif (2008) aponta e questiona a existência do processo de desindustrialização na economia brasileira, a partir de duas hipóteses que o autor considera clássicas nesse tipo de análise. Segundo o autor indica a desindustrialização pode ocorrer "seja pela via "natural", que costuma atingir um país quando este transita para estágios mais avançados de desenvolvimento econômico, seja pelo contágio precoce de uma "nova doença holandesa"10, que acarreta o retorno a um padrão de especialização produtiva e exportadora baseado em produtos intensivos em recursos naturais" (NASSIF, 2008, p.93).

No entanto, e justificando o porquê indicamos a desindustrialização apenas como uma possibilidade no parágrafo acima, consideramos de um lado prematuro as análises que já asseveram a indicação da desindustrialização do Rio de Janeiro a partir da análise dos dados dos últimos 4 a 5 anos. Afirmamos isso porque se trata, em primeiro lugar, de um período curto que pode estar mais atrelado à crise estadual do que realmente a determinação de uma dinâmica duradora. Assim, considera-se necessário analisar um período maior para afirmamos com mais segurança à míngua industrial fluminense.

Por outro lado, e ainda relacionado com o questionamento que apresentamos sobre a desindustrialização, temos dúvidas também, e aqui expomos mais para o debate essa perspectiva, se há sentido ainda em analisar setorialmente a produção em momento de tão profunda integração setorial.

Dito de outra forma, dada todas as transformações produtivas relacionadas com a reestruturação, seguir o debate da indústria em separado das demais atividades (em especial da atividade de serviços), como a análise do processo de desindustrialização sugere, nos parece que faz cada vez menos sentido. Esse é um debate que segue aberto a discussão e apenas pontuamos aqui para problematizar a questão sem ter ao certo uma resposta objetiva sobre ela.

Voltando para a análise dos dados, no cenário regional o período compreendido entre 2002 e 2017 o Vale do Paraíba Fluminense apresentou um crescimento contínuo do número de estabelecimentos industriais. Nesse período, segundo dados da RAIS, a região recebeu um incremento de $35 \%$ no número de estabelecimento das indústrias de transformação, sendo a segunda região de maior dinamismo econômico industrial, atrás apenas da Região Metropolitana do Rio de Janeiro.

Em relação ao valor adicionado bruto industrial a região, segundo dados do IBGE $^{11}$ para o período entre os anos de 2002 a 2016, apresentou crescimento de praticamente $50 \%$ do valor. Apesar disso, os anos mais agudos da crise econômica estadual, especialmente entre 2014 a 2016, o valor adicionado bruto industrial também apresentou decréscimo absoluto com destaque para os municípios de Resende, Porto Real e Volta Redonda, os mais industrializados da região. 
Outro dado de destaque da região do Vale do Paraíba fluminense são os investimentos anunciados na região. Entre 1996 a 2016 foram indicados, segundo dados do Companhia de Desenvolvimento Industrial do Rio de Janeiro (CODIN) e Federação de Indústrias do Rio de Janeiro (FIRJAN), 41 investimentos na região entre implantação e expansão/modernização da indústria, sendo a segunda região fluminense que mais recebeu investimentos nesse período. Parte considerável desse número está atrelada a indústria automobilística e são investimentos privados. Analisaremos com maior detalhamento a implantação e expansão do capital produtivo associado ao ramo automotivo na próxima sessão desse texto.

Além da questão estatística e partindo agora para uma reflexão mais qualitativa da produção regional, o Vale do Paraíba Fluminense também se diferencia no tocante à implantação de novos processos produtivos e a novos produtos. Ou seja, a região tem a inovação como um elemento importante do seu dinamismo econômico.

Inovação ${ }^{12}$ deve ser entendida, como aponta Katz (1997), como algo implícito no desenvolvimento das forças produtivas capitalistas e, portanto, só pode ser entendida colocando em evidência as estratégias de acumulação do capital.

Ainda que inerente ao sistema capitalista e, nesse sentido, destituído de qualquer grau de originalidade na contemporaneidade, não podemos negar, como apontam Arocena e Sutz (2003), que desde o final do século passado vivemos um período de aceleração inovativa. Isso significa reconhecer, segundo os autores, "que en los últimos 50 o 60 anos la sucessión de transformaciones mayores, provenientes de los más diversos âmbitos de la producción y com impactos variados sobre vida y costumbres, tuvo uma rapidez no conocida em outro momento histórico" (AROCENA; SUTZ, 2003, p.78).

Claro está que a inovação realizada na região possui forte vinculação com a presença na região de empresas de grande porte e de capital transnacional do ramo metalmecânico. Assim estão presentes na região estratégias de inovações organizacionais, quando há adoção de práticas novas ou substancialmente melhoradas na gestão da empresa, inovações de processo, atreladas a uma nova forma de produção e inovações de produto, quando a empresa passa a produzir algo novo ou substancialmente melhorado ao menos para a própria empresa.

Apesar da indicação em separado dos três tipos de inovação, que seguem a tipologia de inovação sugerida pela Organização de Cooperação para o Desenvolvimento Econômico (OCDE) e adotada no Brasil pelo $\mathrm{IBGE}^{13}$, o mais comum é que os processos se interliguem e se retroalimentem.

Do ponto de vista da abrangência geográfica da inovação, tipologia criada por Freeman e Perez (1988) e amplamente utilizada nas pesquisas que abordam essa temática, a região do Vale do Paraíba Fluminense também apresenta elevado destaque.

De acordo com as pesquisas de inovação brasileira, e podemos citar aqui algumas como Tunes (2015), Arbix (2007) e Cassiolato e Lastres (2008), prevalece a inovação incremental na maior parte das empresas que buscam uma diferenciação do processo, do produto, da gerência ou do marketing no Brasil. Inovações incrementais são aquelas de menor abrangência geográfica, que se constituem como novas apenas no âmbito da empresa, mas já são amplamente conhecidas no mercado nacional e internacional.

As inovações incrementais são geralmente adaptações de produtos ou processos para o mercado regional ou mesmo para o âmbito interno da empresa. Estão mais ligados, muitas vezes, a busca pela diminuição do custo de produção do que realmente em criar algo paradigmático no mercado.

No entanto, ainda que esse perfil seja majoritário na inovação realizada no Brasil, na região do Vale do Paraíba Fluminense encontramos com maior frequência inovações 
radicais, que são as inovações de elevada abrangência geográfica, ou seja, que se constituem como novas em âmbito mundial.

Certamente essa característica advém da instalação na região de indústrias transnacionais, de capital estrangeiro, de grande porte e inseridas nas redes mundiais de circulação de mercadorias acabadas e semi-acabadas.

Em síntese, infere-se pelo levantamento de dados da indústria apresentados aqui e pela natureza diferenciada da produção que a região do Vale do Paraíba fluminense tem se reafirmado ${ }^{14}$ como um importante polo de atração de investimentos produtivos, notadamente àquele associado ao setor metal-mecânico, na contramão da atual dinâmica produtiva do estado.

\section{Da industrialização fordista do século $\mathrm{XX}$ à reestruturação produtiva contemporânea na região}

A região do Vale do Paraíba fluminense possui um desenvolvimento histórico da indústria que inclui a passagem de um modelo de industrialização tipicamente fordista de meados do século passado à atual flexibilidade de parte dos processos produtivos evidenciando o desenrolar da reestruturação produtiva e a inserção da região nas redes de inovação mundiais.

Da forma como escrevemos acima nos dá uma ideia de ruptura do processo de industrialização na região. Foi de um jeito no passado e agora passa a ser de outra forma. $\mathrm{Na}$ verdade, ainda que isso também seja verdade já que a região tem recebido desde o final do século passado uma produção industrial que rompe com os paradigmas fordistas e implementa a flexibilidade produtiva e do capital, precisamos relativizar essa afirmação lembrando que a expressão reestruturação está ligada mais a mudanças parciais e transitórias do que definitivas e seminais.

Entende-se assim, como Soja (1993, p.194) aponta, "a reestruturação se enquadra entre a reforma parcial e a transformação revolucionária, entre a situação de perfeita normalidade e algo completamente diferente".

O objetivo dessa parte do texto é justamente discutir a reestruturação produtiva da região do Vale do Paraíba fluminense como um paradigma chave para a compreensão das transformações espaciais recentes da região. Para isso recorre-se a um breve estudo da histórica econômica da região, em diálogo com autores que também pesquisaram a região e embasados ainda na realização de trabalho de campo, buscando compreender o pretérito desenvolvimento industrial e analisa-se o atual padrão de desenvolvimento produtivo regional.

A região do Vale do Paraíba Fluminense é uma região que, segundo Davidovich (2001), historicamente se industrializou de forma significativa impulsionada pela siderurgia a partir da década de 1940 com a instalação da CSN (Companhia Siderúrgica Nacional).

Ainda que a instalação da CSN seja um momento marcante para a região é importante que se diga que a indústria já se fazia presente anteriormente a essa data. Como Santos (2010) aponta a indústria têxtil foi a primeira se desenvolver na região, ainda em meados da década de 1920, e possui forte vinculação com as atividades agrárias da região com destaque para o ciclo do café que marcou a paisagem local de forma bastante significativa.

Até a privatização, a CSN adotou uma estratégia produtiva conhecida por "cinturão de fornecedores" (Batista, 2006) que consistia no comprometimento por parte da empresa de adquirir produtos e contratar serviços de fornecedores instalados na região. 
Isso impulsionou a abertura de empresas complementares e fornecedores de insumos na região levando a um acelerado processo de industrialização regional.

Com a privatização da CSN e a adoção do Plano de Atualização e Desenvolvimento Tecnológico (PADT) em 1995, a empresa reestruturou a produção industrial enxugando força de trabalho, alterando a estrutura organizacional e abandonando a política de cunho regional. Tal situação levou, ao longo da década de 1990 e início dos anos 2000, ao fechamento de inúmeras empresas na região levando a sociedade local a enfrentar um significativo quadro de crise econômica alavancada pela falta de empregos na região.

A partir do final do século passado, e mais fortemente ao longo das primeiras décadas do século XXI, a região tem recebido uma série de novos investimentos industriais que, ao mesmo tempo em que reforçaram o perfil industrial da área também representaram um novo momento no processo de industrialização da região, a tal ponto que muitos autores, como Bentes (2017) e Batista (2006), denominam de uma "reindustrialização" da região.

Esse novo momento do processo de industrialização, que entendemos mais como uma evidência da reestruturação produtiva na região ${ }^{15}$, tem como marco inicial o ano de 1996 com a instalação da Volkswagen no município de Resende seguida de uma série de outras automobilísticas como a PSA Peugeot-Citroën em Porto Real, a Hyundai em Itatiaia, a Jaguar-Land Rover em Itatiaia e Renault-Nissan em Porto Real.

Além das automobilísticas, uma série de outras indústrias que produzem bens intermediários também se instalaram na região. Destaque para a indústria de vidros norteamericana Guardian em Porto Real, a GalvaSud que é uma joint venture entre a CSN e o grupo Thyssen Krupp que produz bobinas de aço galvanizado para abastecer as automobilísticas e a Michelin, empresa francesa do ramo de pneus.

A instalação desse conjunto de empresas de grande porte e com atuação global na região marca o início do processo de reestruturação produtiva e espacial reafirmando, como dissemos a pouco, o perfil industrial regional.

"No ambiente econômico e político altamente competitivo da época, a instalação da Volkswagen Resende foi um marco importante para recuperação da condição industrial do Vale do Paraíba Fluminense, possibilitando, ao mesmo tempo, a reinserção dessa região no movimento econômico e produtivo do país." (BENTES, 2017, p.123)

$\mathrm{O}$ entendimento desse novo impulso industrial da região deve passar necessariamente pela análise da atuação do Estado tanto em nível federal, estadual e até municipal. Como Harvey (2005) discute na atual fase do capitalismo cabe ao Estado o empenho em remover barreiras em favor do movimento ampliado do capital para assim "sustentar a relação básica entre capital e trabalho" (HARVEY, 2005, p.82). É nesse sentido que ação do Estado, nas três esferas, contribuiu para a atração dessas empresas para essa região.

Do ponto de vista do governo federal é importante lembrar da política setorial para o ramo automobilístico que ficou conhecida como Novo Regime Automotivo (1994) e o programa "Inovar-Auto" de 2013 a 2017. Ambos, ainda que com atuações diferentes, buscavam a atração da indústria automobilística com o objetivo de transformar o país no maior produtor de veículos da América Latina e impulsionar a produção nacional de componentes e peças complementares à produção.

O governo fluminense, por sua vez e segundo informações obtidas em Batista (2006), com atuação conjunta com os municípios da região, ofereceram incentivos fiscais, isenção de impostos estaduais por mais de 10 anos, liberação de impostos municipais, isenção da taxa da água por 15 anos, instalação de infraestrutura viária da porta da indústria à Dutra, melhoria e modernização dos Portos e da Dutra para garantir a 
circulação do produto e da matéria-prima, qualificação da força de trabalho (inclusive com a abertura de campus avançado da UERJ na área de Engenharia de Produção e da UFF com a Escola de Engenharia Industrial) e doação do terreno. Tais medidas confirmam a entrada do estado do Rio de Janeiro na chamada "guerra fiscal" que beneficia o capital com a diminuição dos custos de produção, ao mesmo tempo em que penaliza a sociedade com a renúncia fiscal.

Paradigmático também, evidenciando uma vez mais o que Harvey (2005) aponta sobre a atuação do Estado capitalista, é que a decisão locacional da maior parte dessas empresas, e podemos citar duas em que esses processos são amplamente conhecidos (a Volkswagen e a PSA Peugeot-Citroën), foi norteada por pesquisas de mercado em que a empresa inqueria as prefeituras e governos estaduais sobre as condições de infraestrutura e de instalação na região. Assim, tomando por base as informações levantadas e pressionando a apresentação de modernização das infraestruturas, a empresas decidiram pela localização no Vale do Paraíba fluminense ${ }^{16}$.

Esse conjunto de empresas instalados mais recentemente na região impulsionaram o crescimento econômico dos municípios com destaque para Porto Real, Resende e Volta Redonda. Em Porto Real, município desmembrando em 1995 de Resende e que tem a sua emancipação relacionada a atuação de um grupo privado local, entre 2007 e 2012, segundo dados do Condin, o crescimento do ICMS foi de 132\%. O PIB municipal em 2010, segundo dados do IBGE, foi de 4,82 bilhões de reais, o $6^{\circ}$ maior do país.

Avante a questão das estratégias locacionais e o impulso econômico estimulado por essas empresas, a incorporação de estratégias de produção diferenciadas, as inovações organizacionais, marcam de maneira significativa $\mathrm{o}$ movimento associado à reestruturação produtiva.

De Mattos (1998) aponta três principais transformações estruturais associadas à reestruturação produtiva. A primeira é a autonomização do capital que, em outras palavras, significa o descolamento da valorização do capital das atividades produtivas. De Mattos (1998) chega a falar de um divórcio do mercado de capitais com a produção de mercadorias no sentido do que Marx (1985[1867]) apontou sobre os processos de capitalização.

Nesse sentido, o autor aponta os atuais protagonistas da vida econômica como os conglomerados que através de fusões, aquisições, joint-ventures dirigem a economia regional e nacional.

A segunda é a transformação de morfologias organizativas da empresa. Isso significa, em outras palavras, na adoção de estratégias flexíveis da organização da empresa que passa a atuar em redes. Essa característica apontada pelo autor se assimila ao que Benko (1995) aponta como sendo "desintegração vertical" e Lipietz e Leborgne (1988) tratam como "quase integração vertical".

Segundo Benko (1995, p.141) "fala-se de desintegração vertical de uma empresa quando as diferentes etapas da produção não se efetivam na mesma empresa”. Lipietz e Leborgne (1988, p.23) na mesma perspectiva propõem o conceito de quase-integração vertical, em que “(...) relações estáveis entre fornecedor e clientes, importante participação do cliente no volume de negócios do fornecedor, campo de subcontratação, formas não mercantis de relação interfirmas, indo da subordinação à parceria fazem com que essas empresas juridicamente independentes assemelhem-se a uma só empresa”.

A adoção das estratégias não mercantis, como a subcontratação, as parcerias e a cooperação, multiplicou o número de empresas que, ainda que independentes, trabalham e produzem de forma subordinada à grande empresa. É como se um setor da empresa, responsável por uma parte da produção da mercadoria, passasse a ser uma empresa 
juridicamente independente. E é exatamente isso que ocorre na produção interna dessas empresas na região.

O terceiro ponto indicado por De Mattos (1998) como significativo do processo de reestruturação produtiva é a intensificação da terceirização do aparato produtivo com a externalização de um elevado número de atividades que passam a ser contabilizadas como de serviços. Essa é praticamente uma consequência direta do anterior em que diferentes capitais se entrecruzam no processo produtivo, no entanto revelam um aspecto que consideramos essencial para compreender o capital produtivo na atualidade: a não distinção setorial do capital.

Hirschhorn (1987) há bastante tempo já chamou a atenção para esse aspecto da reestruturação produtiva. Segundo o autor “(...) podemos caracterizar esse período (recente), não tanto pelo declínio da indústria e pela ascensão do terciário, mas antes pelas modificações da relação existente entre esses dois setores. Com efeito, nem o sector industrial desapareceu, nem os serviços substituíram a produção de bens". (HIRSCHHORN, 1987, p.8).

Jimenéz e Utrilla (1992) de forma semelhante também expressaram essa perspectiva nas palavras abaixo

\begin{abstract}
las transformaciones recientes del sistema socioeconómico han tornado obsoleta y reducido la capacidad explicativa de la formulácion sectorial, aunque la inercia de su uso universal haga que sus nociones se deslicen de forma impercitible; asimiesmo la producción estadística de información há estado, y está, prefigurada por este modelo, por lo que aquélla puede resultar inconveniente e incompleta para compreender las nuevas tendências (JIMENÉZ; UTRILLA, 1992).
\end{abstract}

João Ferrão (1992) destacou também esse aspecto da integração entre os serviços e a indústria e apontou dois fatores explicativos para justificar a realização de uma pesquisa com uma "visão transsetorial". O primeiro motivo é a intensificação da divisão do trabalho e o segundo a desmaterialização dos processos produtivos como a automatização e as novas tecnologias da informação.

Kon (2015) é outra autora que ao discutir o que ela denominou a nova economia política dos serviços também questiona a distinção clássica setorial entre as frações do capital. No trabalho da autora há uma profunda análise sobre o papel dos serviços no movimento de acumulação do capital em que autora aponta, dentre outras questões, a negligência que os estudos econômicos têm com os serviços. Mas que, no entanto, essa situação tem se alterado de forma mais recente justamente pelo hibridismo setorial do capital nas grandes empresas, sobretudo na relação com os processos de inovação.

Como já citado antes, a inovação está presente na maior parte dessas empresas que contam com departamentos de pesquisa e desenvolvimento (P\&D) diretamente conectados aos respectivos departamentos globalmente distribuídos constituindo uma rede de compartilhamento de conhecimentos e de atuação global. Parte significativa da inovação realizada em âmbito regional é incremental composta por adaptações de produtos mundiais ao mercado latino-americano.

No entanto há exceções como, entre outras, a inovação organizacional de âmbito mundial implantada pelo MAN Latin America ${ }^{17}$ denominada de "Consórcio Modular" e a inovação de produto da Peugeot também mundial com a produção do novo automóvel da empresa, a Pickup Peugeot Hoggar, na fábrica da PSA em Porto Real.

O caso do Consórcio Modular da MAN é paradigmático para sustentar o argumento da reestruturação produtiva na região. Esse consórcio pode ser considerado uma grande inovação organizacional, pioneira para a empresa em âmbito mundial, que 
articula um grupo de fornecedores de primeira linha, denominados de sistemistas do consórcio, ligados diretamente à empresa e localizados, em alguns casos, dentro da fábrica, na montagem de subconjuntos dos veículos.

No site da MAN Latin America, a apresentação do Consórcio por parte da empresa é feita da seguinte forma:

oito parceiros fazem a montagem de conjuntos completos de peças. São eles a Maxion (que cuida da montagem do chassi), a Arvin Meritor (eixos e suspensão), a Remon (rodas e pneus), a Powertrain (motores), a AKC (armação da cabine), a Carese (pintura) e a Continental (acabamento da cabine). $\mathrm{O}$ controle de qualidade do produto é de total responsabilidade da MAN Latin America ${ }^{18}$.

O esquema abaixo apresenta de forma mais clara a organização produtiva da empresa através do Consórcio Modular em que podemos verificar as 3 características apontadas por De Mattos (1998) como significativas para a compreensão dos processos de reestruturação produtiva.

Figura 1 - Representação esquemática do consórcio modular da MAN Latin America

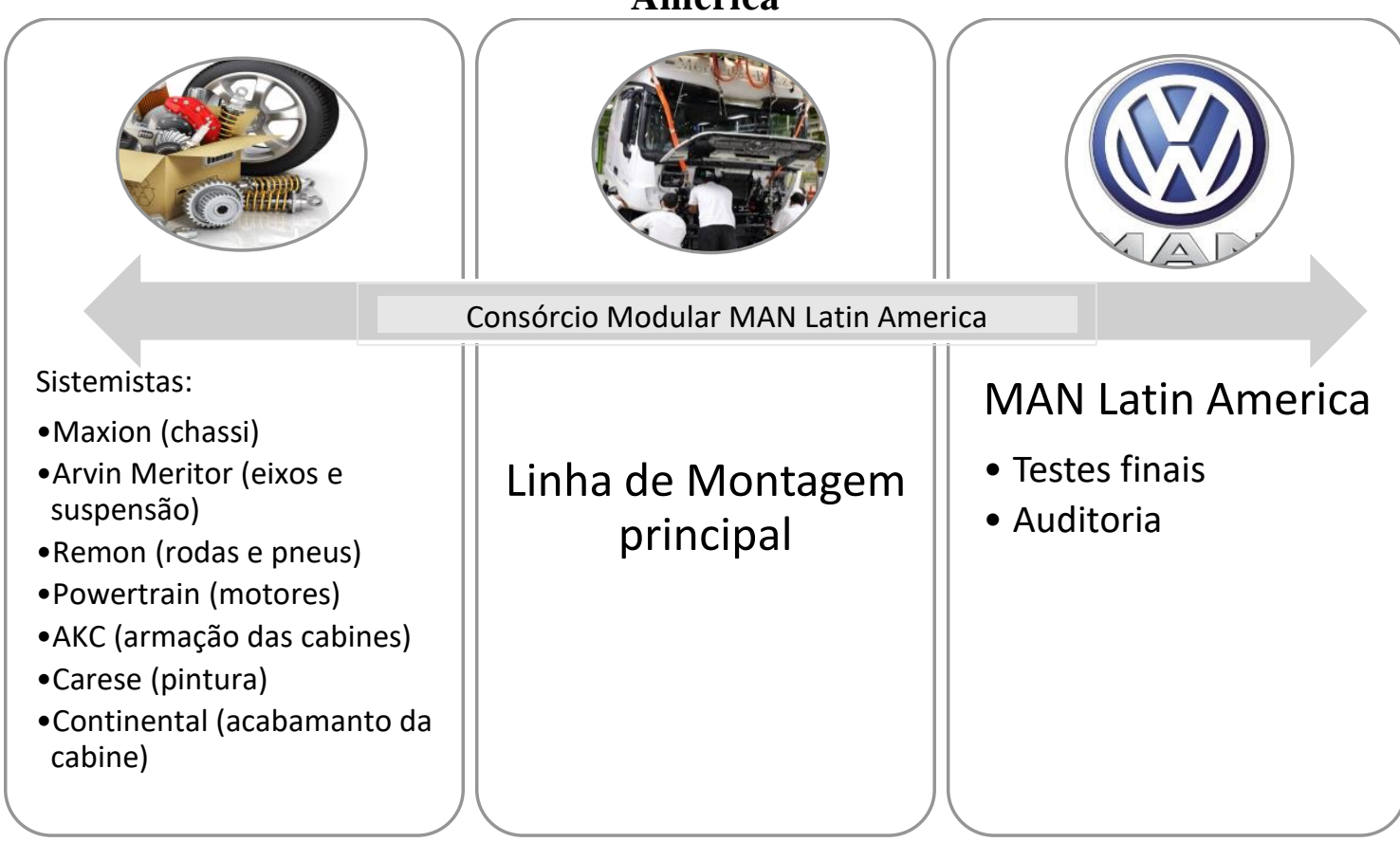

Fonte das informações: MAN Latin America. Disponível em:

https://www.vwco.com.br/institucional/consorcio-modular. Acesso em 01/05/19.

Org. da autora.

Em matéria vinculada no jornal A Folha de São Paulo sobre as diferentes estratégias produtivas das empresas instaladas na região a reportagem, tomando por base uma entrevista com engenheiros da MAN, descreve a organização produtiva da seguinte forma.

São três os marcos mais importantes dessa evolução. Com o "just-in-time", começa a se estabelecer uma real parceria entre as partes, na qual ambas passam a compartilhar objetivos comuns de produtividade e qualidade de projeto e operação. $\mathrm{O}$ fornecimento em módulos hierarquiza e reduz a cadeia de fornecedores diretos às montadoras. Finalmente, a montagem compartilhada significa o fim da montagem convencional, conceito em que os 
fornecedores "entram na fábrica" e se envolvem mais profundamente com os riscos do próprio negócio de montagem. (CARVALHO, R.; MARX, R. $\left.1995^{19}\right)$

Observa-se no esquema, primeiramente, a produção descentralizada do ponto de vista organizacional. Isso significa em outras palavras que para a produção do veículo, nesse caso caminhões que é a especialidade da unidade fabril de Resende, há uma cooperação entre diferentes capitais que atuam em rede para a finalização do produto, denotando a adoção da "desintegração vertical" como parte da estratégia de produção.

A adoção dessa estratégia de produção acaba por explicitar que "a fronteira entre serviços e outras atividades ou produtos pode ser questionada, de modo que em certas produções é difícil identificar qual parte do processo produtivo foi responsável pela geração de valor do produto" (KON, 2015, p.198).

Por fim, essas empresas que atuam diretamente na produção de peças ou na cooperação direta com a MAN Latin America, as chamas sistemistas, evidenciam as estratégias financeiras associadas ao conglomerado da MAN. Parte delas atuam como joint venture, espécie de cooperação entre empresas diferentes que atuam de forma integrada em certas situações ou projetos específicos. Além desta, há na região outras empresas que utilizam estratégias financeiras semelhantes com atuação na região e em rede na estrutura produtiva mundial dessas empresas.

É possível evidenciar elementos da reestruturação produtiva regional a partir de outros exemplos nas demais grandes empresas localizadas na região. Porém, para os objetivos dessa parte do texto, consideramos emblemático o caso explicitado que reforça o aprofundamento do processo de reestruturação produtiva regional.

\section{Novos arranjos produtivos: transformações espaciais e metropolização regional}

Transformações tão significativas na produção, como as que evidenciamos acima, claramente, possuem imbricações espaciais. Não aqui no sentido de impactos espaciais, como se o espaço fosse um dado natural e apenas receptáculo da dinâmica social, mas sim no sentido do espaço como produto, meio e condição das relações sociais e que, portanto, será transformado no movimento da sociedade.

Destaque em termos de transformação espacial a dois pontos que vamos aqui debater. Por um lado, há um intenso movimento do capital imobiliário na região com a implantação tanto de novos condomínios residenciais, loteamentos, intensa verticalização e conjuntos habitacionais como o Minha Casa, Minha Vida.

Por outro, há uma questão relevante a ser pensada que é a localização desses novos empreendimentos. Parece-nos, e vamos aqui discutir alguns pontos sobre essa questão, que há uma reestruturação também no sentido de pensar a região como um espaço de fluxos e de conexão com o que está fisicamente distante ainda que conectado em redes materiais e imateriais.

Isso significa pensar que as recentes transformações urbanas regionais evidenciam o processo de metropolização do espaço que, em certo sentido, nega o urbano antigo e produz novas formas urbanas e novos usos do espaço distintos dos já existentes e conectados em redes com a lógica metropolitana.

O capital imobiliário, como sabemos, é uma das frações que possui a maior potência de transformação do espaço. Isso porque produz espaço do ponto de vista sctrictu. É também, em certa medida, a fração do capital que mais claramente evidencia em uma cidade que há um movimento de ascensão econômica com poder de transformação significativa do urbano. 
Dizemos isso porque o movimento do capital imobiliário na cidade é facilmente reconhecível na paisagem através das campanhas de marketing e divulgação dos novos empreendimentos comerciais ou residenciais. Também porque os novos equipamentos imobiliários podem transformar o modo de vida cotidiano dos residentes, atraindo uma parte da população a ocupar novos lugares e ao instituir novas formas de consumo e de lazer com a expansão dos shopping centers e centros comerciais de grande porte.

Na região temos tanto condomínios residenciais destinados à ocupação por uma classe média alta como também novos projetos habitacionais como o Minha Casa, Minha Vida. Os condomínios residenciais são uma novidade para a região e estão, na maior parte dos casos, afastados do tecido urbano central e conectados através de grandes e largas avenidas que, durante os períodos de pico da manhã e do final de tarde, apresentam fluxo intenso de veículos particulares. A proliferação desse tipo de equipamento denota uma elevação da renda das famílias que podem estar associado ao crescimento econômico regional recente.

O Minha Casa, Minha Vida, projeto de habitação popular que integra participação do governo federal e de empreendedores locais, seguindo lógica parecida ainda que diametralmente oposta à anterior ${ }^{20}$, também se situa distante do centro urbano regional e próximo às estradas regionais.

Os shopping centers, ainda que já existentes nos municípios da maior parte da região, são outro equipamento urbano que denota transformações relevantes na dimensão espacial. Isso porque há uma proliferação de novas unidades, ao mesmo tempo em que, uma mudança estratégica na localização. Se antes o centro urbano era o local de maior demanda para a localização desses equipamentos, atualmente os novos empreendimentos evidenciam a preferência para áreas afastadas do centro urbano, próximas aos equipamentos de fluxos de circulação regional.

Por outro lado, a própria localização dos novos empreendimentos industriais reforça também as transformações espaciais. Se antes a indústria, como a CSN, estava localizada na área central do município de Volta Redonda, a partir de onde o município expandiu a sua área urbana e atraiu inúmeros equipamentos urbanos, como o primeiro shopping center da cidade e a maior parte dos estabelecimentos comerciais e de serviços, agora, os novos empreendimentos industriais, estão completamente deslocados da área urbana, distantes tanto do ponto de vista físico como também em relação a mobilidade urbana.

Em Porto Real, município que como vimos recebeu muitos novos empreendimentos industriais, as novas plantas distam mais do que $5 \mathrm{~km}$ do centro da cidade. Estão não apenas distantes do ponto de vista físico, como também isolados em uma grande área denominada de Tecnopolo 1 que se assemelha a concepção de um parque industrial. Em trabalho de campo realizado no município ficou evidente a dificuldade de mobilidade do centro da cidade para os empreendimentos. Apenas uma linha de ônibus conecta essas duas áreas e, segundo relatos dos trabalhadores entrevistados, é irregular e extremamente demorada.

Em Resende a mesma lógica. Ainda que com a área urbana significativamente maior do que a de Porto Real, as novas plantas industriais estão localizadas distantes da área urbana. Em ambos, Porto Real e Resende, as vias de circulação que chegam as plantas industriais conectam mais rapidamente a área à Dutra do que ao centro dos respectivos municípios.

Parece-nos que esses indícios comprovam uma reestruturação espacial em marcha. Novos usos do espaço e novas formas do urbano estruturadas sob uma lógica que não privilegia mais as relações locais. Ao contrário disso, ao anteferirem um espaço de 
fluxos conforma um espaço difuso, evidenciando a importância da conexão com outros espaços para além do âmbito regional estrito.

Pereira (2013) sintetiza muito bem o que estamos evidenciando ao afirmar que "esse conjunto de produtos, formas de produção e apropriação imobiliária configura a emergência do espaço metropolitano e dissolução do urbano da cidade antiga" (PEREIRA, 2013, p.105).

Dessa evidência empírica surge a conexão com o processo de metropolização do espaço (Lencioni, 2004) ou também denominado de urbanização regional (Soja, 2013). Essa região é em essência o elo do tecido urbano metropolitano das duas metrópoles Rio de Janeiro e São Paulo - que se expandem na contemporaneidade dando forma ao que vem sendo denominado de megarregião (Lencioni, 2015). Por ela passa a rodovia Presidente Dutra, um dos maiores eixos rodoviários e ferroviários do país, responsável por grande parte da circulação de mercadorias e pessoas da região.

A megarregião Rio de Janeiro - São Paulo, região esta que engloba desde o norte fluminense, passando pela Região Metropolitana do Rio de Janeiro e região das serras, chegando ao Vale do Paraíba Fluminense e paulista, adentrando o território paulista desde o litoral norte até Santos, subindo a serra do Mar e atingindo mais ao nordeste paulista a região de Campinas. Trata-se de uma região ainda de contornos confusos e que apresenta, como sabemos, o maior dinamismo socioeconômico do país, a concentração da sede das maiores empresas brasileiras, a maior renda per capita, o maior poder de consumo e, contraditoriamente, as condições de vida que revelam a maior desigualdade socioeconômica do país.

A metropolização do espaço, segundo Lencioni (2015), é a nova determinação histórica do urbano que associa a continuidade do processo de urbanização com a ruptura dele. Trata-se de produção do urbano, porém sob nova natureza já que não se refere mais simplesmente a criação de cidades ou estruturação de redes urbanas. Estamos agora, como aponta a autora, diante de um processo de mudanças estruturais que apresentam formas e funções renovadas do urbano que mantém a lógica da reprodução do capital, no entanto agora submetida à hegemonia das finanças e atreladas ao processo de reestruturação produtiva.

Assim, além da questão linear do crescimento da megarregião englobar necessariamente a região do Vale do Paraíba fluminense, acreditamos que os novos arranjos espaciais regionais, frutos da reestruturação espacial, evidenciam transformações recentes na região em consonância com a metropolização do espaço.

\section{Considerações Finais}

Sabemos que todo capital transforma e produz o espaço. O capital produtivo, que não age de forma isolada das demais frações do capital, ainda que não se constitua hoje como hegemônico nas relações capitalistas contemporâneas segue sendo parte constituinte do movimento do capital e da estruturação do urbano metropolitano.

Discutimos nesse texto o movimento do capital produtivo na região do Vale do Paraíba fluminense que recentemente tem sentido mais de perto as transformações associadas a reestruturação produtiva e espacial com a implantação na região de um novo polo automobilístico no Brasil.

A reestruturação produtiva foi evidenciada no texto através do debate da incorporação de inovações organizacionais, de produto e de processo no âmbito direto da produção do automóvel e de outros componentes. Trata-se, destacando outro ponto, de pensar a produção da mercadoria sem as amarras setoriais e a partir da perspectiva da produção em rede mundial. 
Já a reestruturação espacial, muito relacionada com a nova forma de produção que alterou de sobremaneira as relações sociais, foi salientada pela produção do espaço regional sob a nova lógica da metropolização do espaço. Assim novos equipamentos urbanos, pensados para atingir uma classe social específica, com distinta lógica de localização foram construídos nos municípios de maior parte da região integrando-os a uma perspectiva que fragmenta os limites regionais rígidos e antigos em prol de pensar uma região como produto, condição e meio do processo de metropolização do espaço.

Dessa forma, de um lado a reestruturação produtiva e, de outro as transformações do espaço na região, comprovam a relação imbricada entre espaço e economia apontado a importância e a necessidade de análises que privilegiam, a partir de um olhar crítico da produção do espaço, as estratégias e ações dos agentes econômicos regionais.

\section{Notas}

1 - Projeto de Pesquisa que conta com auxílio financeiro do CNPq a partir do Edital Universal 2018 para o período de 2019 a 2021.

2 - Acredita-se na importância de compreender hoje as atividades produtivas a partir de uma perspectiva transsetorial que entende a produção diretamente atrelada à mercadoria, mas sem a distinção setorial clássica.

3 - Entende-se por estudos de casos as pesquisas que buscam compreender um processo ou fenômeno social e escolhem um recorte territorial para análise. Ou seja, parte-se de uma totalidade do fenômeno e busca na análise regional uma parte ou um exemplo do fenômeno ou processo estudado.

4 - A referência à inovação relacionada a indústria de transformação é relevante no Rio de Janeiro porque a indústria extrativa possui importância significativa a partir do refino e industrialização do petróleo. Ainda que importante do ponto de vista das inovações atreladas a ela, trata-se de uma produção específica.

5 - Dados obtidos no Portal Cidades do IBGE. Disponível em: https://cidades.ibge.gov.br/.

6 - Dados de estabelecimentos da indústria de transformação conforme a CNAE 2.0 Seção disponível em http://pdet.mte.gov.br/acesso-online-as-bases-de-dados

7 - Segundo dados disponibilizados no site IndexMundi, o período de outubro de 2014 a janeiro de 2016 registrou forte queda contínua do preço do petróleo. As maiores quedas foram em janeiro de 2015 com uma desvalorização de mais de $20 \%$ do barril e janeiro de 2016 com redução pouco maior do que $18 \%$. Dados disponíveis em: https://www.indexmundi.com/pt/pre\%C3\%A7os-demercado/?mercadoria=petr\%C3\%B3leo-bruto\&meses $=300$

8 - Claro que a crise econômica que assolou o estado, e que comprometeu até mesmo as condições de pagamento dos salários dos servidores públicos estaduais, tem um contexto muito mais amplo do que o citado aqui. Não desconhecemos que a dinâmica negativa envolve também os custos associados aos grandes eventos, desvio de verbas públicas dentre outras condicionantes que não nos cabe aqui aprofundamento.

9 - IBGE, Pesquisa Industrial Anual - Empresa, 2013 a 2016.

10 - A expressão "doença holandesa", bastante utilizada na bibliografia da área econômica ligada às análises de desindustrialização, faz referência ao ocorrido na Holanda a partir dos anos 1960 em que o país apresentou decréscimo relativo da atividade industrial em detrimento do aumento da participação de atividades primárias. No caso holandês o aumento nos preços do gás impulsionou a produção e exportação dessa matéria-prima.

11 - Dados disponibilizados no Portal Cidades do IBGE. Disponível em: https://cidades.ibge.gov.br/.

12 - Importante esclarecer aqui que hoje a expressão correta é apenas inovação. E não mais inovação tecnológica. Isso segue os procedimentos internacionais e se justifica pela necessidade de diferenciação entre o processo de inovação e a adoção de tecnologias avançadas.

13 - A OCDE possui um manual que regula os procedimentos metodológicos da pesquisa sobre inovação chamado de Manual de Oslo que está atualmente na $4^{a}$ edição publicada em 2018. O IBGE, através da Pesquisa de Inovação (PINTEC) utiliza os procedimentos metodológicos sugeridos pela OCDE, o que garante a possibilidade de comparação internacional entre os dados, além de uma segurança e confiabilidade maior das informações estatísticas.

14 - Reafirmado porque essa região tem um histórico processo de crescimento econômico e desenvolvimento regional atrelado ao processo de industrialização desde início do século XX.

15 - O termo reindustrialização denota a ideia de esvaziamento da atividade industrial em um primeiro momento para depois retomada do processo, entendendo assim como dois momentos estanques, sem relação entre eles. Ao contrário disso, entendemos que o movimento atual do capital industrial para a região 
guarda estreita relação com o momento anterior já que estavam postas condições gerais de produção que viabilizaram a atual reprodução do capital. Por isso preferimos o termo reestruturação.

16 - O trabalho de Ramalho e Santana (2002) apresenta em detalhes os questionários e a competição que isso gerou entre as localidades contatadas pela empresa.

17 - A MAN Latin America foi criada oficialmente em 16 de março de 2009, com a aquisição da Volkswagen Caminhões e Ônibus pela MAN SE (empresa mãe do Grupo MAN). Com uma capacidade total de produção de 80 mil veículos por ano, é a maior fabricante de caminhões, e a seg unda maior de ônibus, da América do Sul.

18 - Informações em https://www.vwco.com.br/institucional/consorcio-modular. Acesso em 01/05/19.

19 - Disponível em: https://www1.folha.uol.com.br/fsp/1995/10/08/dinheiro/4.html. Acesso em 04/05/19.

20 - Oposta no sentido da ocupação do empreendimento. Enquanto os novos condomínios fechados atraem as classes mais altas, o Minha Casa Minha Vida é destinado as classes mais baixas da sociedade.

\section{Referências Bibliográficas}

ARBIX, Glauco. Inovar ou Inovar. A indústria brasileira entre o passado e o futuro. São Paulo, Ed. Papagaio, 2007.

AROCENA, R.; SUTZ, J. Subdesarrollo e innovación. Navegando contra el vento. Madrid: Cambridge University Press, 2003.

BATISTA, Ivone. Redes produtivas e novas territorialidades no Sul Fluminense. Rio de Janeiro, 2006. Tese (Doutorado) - Programa de Pós-Graduação em Geografia do Instituto de Geociências da Universidade Federal do Rio de Janeiro.

BENKO, Georges. Economia, Espaço e Globalização. São Paulo, Hucitec, 1995.

BENTES, Julio. Reindustrialização e transformações urbanas recentes na microrregião do Médio Vale do Paraíba Fluminense e suas cidades médias. In SILVA, W.; SPOSITO, M. Perspectivas da Urbanização. Reestruturação urbana e das cidades. Rio de Janeiro, Consequência Editora, 2017.

BRASIL. Relatório Anual de Indicadores Sociais (RAIS). Ministério do Trabalho e Emprego (MTE). Disponível em: http://portal.mte.gov.br/rais/estatisticas.htm. Acesso em 15/08/19.

CASSIOLATO, J. E.; LASTRES, H. M. Discussing innovation and development: converging points between the Latin American school and the Innovation Systems perspective? Globelics Working Papers Series, 2008. Disponível em: http://www.globelics.org/article/discussing-innovation-and-development-convergingpoints-between-the-latin-american-school-and-the-innovation-systems-perspective/. CLAVAL, P. Geografia econômica e economia. Geotextos, v. 1, n. 1, p. 11-27, 2005. DAVIDOVICH, Fany. Metrópole e território: metropolização do espaço no Rio de

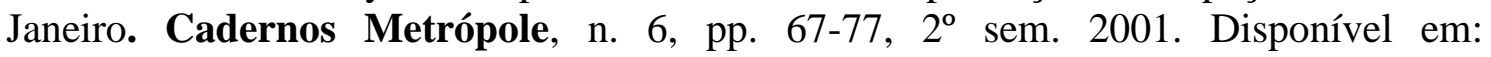
https://revistas.pucsp.br/metropole/article/view/9269/6875. Acesso em 12/08/19.

DE MATOS, Carlos. Reestruturación, crecimiento y expansión metropolitana em las economías emergentes latinoamericanas. In GORESNTEIN; BUSTOS (comps.). Ciudades y regiones frente al avance de la globalización. Bahía Blanca, Universidad Nacional del Sur, 1998.

FERRÃO, João. Serviços e Inovação. Novos Caminhos para o desenvolvimento regional. Oeiras, Celta Editora, 1992.

FREEMAN, C.; PEREZ, C. Structural crisis of adjustment: business cycles and investment behavior. In: DOSI, G.; FREEMANN, C.; NELSOM, R.; SILVERBERG, G.; SOETE, L. (Eds.). Technical change and economic theory. London: Pinter, 1988.

HARVEY, David. A produção capitalista do espaço. São Paulo: Annablume, 2005.

HIRSCHHORN, L. L'Économie Post-Industrielle: quel Travail, quelle Compétence, pour un Nouveau Mode de Production? Économie et Humanisme, n. ${ }^{\circ} 295$, p. 25-43, mainjuin, 1987. 
IBGE. Pesquisa Industrial Anual - Empresa. Rio de Janeiro, IBGE, vários anos. Disponível em: https://www.ibge.gov.br/estatisticas/economicas/industria/9042pesquisa-industrial-anual.html'?t=sobre. Acesso em 14/09/19.

IBGE. Portal Cidades. Rio de Janeiro, IBGE, s/d. Disponível em: https://cidades.ibge.gov.br/. Acesso em 14/09/19.

IBGE. Pesquisa de Inovação (PINTEC). Rio de Janeiro, IBGE, 2000, 2003, 2005, 2008, 2011 e 2013. Disponível em: http://www.pintec.ibge.gov.br/. Acesso em: 13 set. 2011. JIMENÉZ, Antonio; UTRILLA, Severino. Los Servicios y el Territorio. Madrid, Editorial Sintesis S/A, 1992.

KATZ, Claudio. Discusiones Marxistas sobre tecnología, Teoría. Razón y Revolución, n. 3, invierno de $1997 . \quad$ Disponível em: http://www.razonyrevolucion.org/textos/revryr/prodetrab/ryr3Katztecnolo.pdf. Acesso em: 12 abr. 2018.

KON, Anita. Nova Economia Política dos serviços. São Paulo, Perspectiva/CNPq, 2015. LENCIONI, Sandra. Estado de São Paulo: Lugar de concentração da inovação e da intensidade tecnológica da indústria brasileira. In SPOSITO, E (org.). O novo mapa da indústria no início do século XXI. São Paulo, Ed. da Unesp, 2015.

LENCIONI, Sandra. Urbanização difusa e a constituição de megarregiões. O caso de São Paulo-Rio de Janeiro. Rio de Janeiro. eMetropolis, n. 22, 2015 p. 6-15. Disponível em: $<$ http://emetropolis.net/>. Acesso em 03 de novembro de 2015.

LIPIETZ, Alain; LEBORGNE, Danièle. O pós-fordismo e o seu espaço. Espaço e Debates, São Paulo, vol.8, n.25, p.12-28, 1988.

MARX, K. O Capital: crítica da economia política. Tradução de Regis Barbosa e Flávio R. Kothe. Livro 1, v.1. São Paulo: Abril Cultural, 1985 [1867].

NASSIF, A. (2008). "Há Evidências de Desindustrialização no Brasil?". Revista de Economia Política, Vol. 28, N.1. Disponível em: http://www.scielo.br/scielo.php?pid=S0101-31572010000200003\&script=sci_arttext. Acesso em 21/08/19.

OLIVEIRA, Floriano. Reestruturação produtiva, território e poder no Rio de Janeiro. Rio de Janeiro, Garamond, 2008.

PEREIRA, Paulo. Metropolização, reestruturação imobiliária e reconfiguração da cidade de São Paulo. FERREIRA, A. et al. Metropolização do Espaço. Rio de Janeiro, Consequência, 2013.

SANTOS, Milton. Economia Espacial. São Paulo, Edusp, 2003.

SOJA, Edward. Geografias Pós-Modernas. A reafirmação do espaço na teoria social crítica. Rio de Janeiro, Jorge Zahar Editor, 1993.

SOJA, Edward. Para Além de Postmetropolis. Revista da UFMG. Belo Horizonte, v. 20, n.1, p.136-167, jan./jun. 2013. Disponível em: https://www.ufmg.br/revistaufmg/downloads/20/7para_alem_da_postmetropolis_edward_soja.pdf. Acesso em 15/03/19.

SPOSITO, Eliseu. Desenvolvimento regional do Brasil: uma leitura pela ótica da quarta revolução industrial. In OLIVEIRA, F. et al. Espaço e Economia. Geografia Econômica e a economia política. Rio de Janeiro, Consequência, 2019.

TUNES, Regina. Geografia da Inovação no Brasil. Território e Inovação no Brasil no século XXI. Tese (Doutorado). - Faculdade de Filosofia, Letras e Ciências Humanas da Universidade de São Paulo. São Paulo, 2015. 